\title{
Assessment and Evaluation Framework with Successful Application in ABET Accreditation
}

\author{
https://doi.org/10.3991/ijep.v7i3.7262 \\ Issam Damaj $\left.{ }^{\square}\right)$, Ashraf Zaher, and Jibran Yousafzai \\ American University of Kuwait, Safat, Kuwait \\ idamaj@auk.edu.kw
}

\begin{abstract}
The development of reliable and easy-to-deploy assessment plans are a world-wide interest of academic programs. The cultivation of a culture of assessment or engaging in an accreditation effort is dependent on the development of effective assessment frameworks. Examining overly large variety of sources and using different tools challenge the applicability of assessment plans and can prove to be major hurdles. In this paper, a unified framework is proposed that enables the assessment and evaluation of student outcomes, at the program level, and evaluating student performance as well. The proposed framework identifies a set of courses to be assessed using direct tools. The tools enable measurements of attainment scores at the course learning outcomes, performance indicators, and student outcome levels to create a paradigm for unified assessment. The framework was deployed within a two cycles empirical study and led to a successful accreditation of a computer engineering program by ABET. The paper includes a thorough analysis and evaluation of the framework and its application.
\end{abstract}

Keywords-ABET, accreditation, assessment methodology, engineering education, capstone design projects

\section{Introduction}

The rapid growth in number of higher education institutes, all over the world, necessitates exploring frameworks for assessment and evaluation (AE) that promote quality. Program reviews are challenged by the need to satisfy a variety of criteria as mandated by the local, regional, and international quality assurance requirements [1]. Successful program reviews are achieved using assessment plans that are welltailored to fit the characteristics of the programs and their hosting institutions. Many differences exist among academic institutions, such as size, structure, resources, culture, leadership, mission, and scope of available industries. Effective AE frameworks must fit the contextual features of the program and the institution/country, while satisfying the international professional accreditation requirements $[2,3]$.

Lately, the focus of the accreditation process has been shifted to outcome-based assessment (OBA), rather than simply investigating the institutional input variables such as resources, grants, and faculty-to-student ratios. The change in orientation proved to 
be quite challenging particularly regarding the definition, scope and measurement of student outcomes (SOs) [4]. Starting 1995, the new ABET EC-2000 review process required satisfying eleven behavioral outcomes for engineering graduates, commonly referred to as (a) through (k) criteria, in addition to implementing a feedback mechanism that demonstrates continuous improvement to the curriculum [5]. Systemizing SOs assessment and providing tools to robustify the results and illustrating evidences for improvement are challenging and time-consuming processes [6]. While some of the SOs that focus on problem solving and practical application of engineering concepts can be assessed from most technical courses, other SOs with focus on life-long learning, group work effectiveness, and social awareness are more abstract and consequently harder to assess. To enable attainment and assessment, all SOs, educators must actively promote student development in knowledge, skills and behavior. Assessment can then be used to verify the abilities possessed by students and to identify improvements at various levels. However, the development of reliable, thorough, accurate, and easy-to-deploy assessment plans creates a major challenge for educators [7].

Focusing on OBA and satisfying ABET accreditation criteria have led to many innovations in $\mathrm{AE}$ frameworks that intensely impact technical programs world-wide. Existing assessment plans and $\mathrm{AE}$ tools include a bouquet of options that comprises direct and indirect tools, standardized testing, and triangulations from wide-sets of sources [8-11]. While decisions, based on assessment data obtained from a broad range of sources, are reliable and accurate, the process itself is time-consuming and complex. In addition, curricular changes and the cultivation of a culture of assessment can be difficult for a process with such a wide scope.

In this paper, we propose a paradigm that unifies both assessment and evaluation of SO attainments and evaluation of students' performance. Additionally, this paper makes presents a created set of performance indicators (PIs) for each SO. The PIs help in clearly defining the scope of the SOs and facilitate a more localized and targeted mapping of the assessment and evaluation components to the SOs. The proposed framework carefully selects indicators and performance targets to quantify the attainment of each SO and develops robust rubrics to accurately measure the attainment. The framework builds on the regular evaluation of student performance to provide reliable assessment of attainment of SOs at the program level. Although the proposed paradigm is developed within a technical education context with application towards an engineering program, it can be adopted by other disciplines with minor modifications. The framework adopts a bottom-up approach for reusing attainment score measurements of learning outcomes at the course level. The measurements are used for assessing SOs and reused in evaluating student performance. Although the concept of PIs is not new, the proposed framework, as driven by a need for the unification of SO attainment and students' performance, is unique in its structure and in application. The framework was deployed within a two-cycle empirical study and successfully led to accrediting a computer engineering program by ABET at the American University of Kuwait in August 2016.

This paper is organized so that Section 2 presents the research objectives of the paper. The proposed unified AE framework is presented in Section 3. Sections 4 and 5 
present the framework application in accrediting a computer engineering program by ABET and the results. A thorough analysis and evaluation is included in Section 6. Section 7 concludes the paper and sets the ground for future works.

\section{Research Objectives}

The development of reliable and easy-to-deploy assessment plan is the main motivation for the proposed unified assessment and evaluation approach. The need for reliable assessment and evaluation is essential for the accurate identification of opportunities for improvement and closing the assessment loop on solid, valid, and evidence-driven grounds. Moreover, the need for accurate assessment must not compromise the ease-of-deployment; otherwise, the applicability of the plan becomes challenging and can face major hurdles. The research objectives of the current investigation comprise the following:

- The development of a unified framework that enables the assessment and evaluation of student outcomes, at the program and course levels, and evaluating student performance as well.

- The development of PIs that maps to ABET's (a) through (k) SOs.

- The identification of a convenient-to-handle set of courses in a computer engineering program to be assessed using direct tools with special emphasis on capstone design courses.

- The development of learning outcomes for the identified courses that map to the developed PIs

- The formulation of a statistical framework that enables the calculation of attainment scores at the course, PI, and SO levels.

- The description of the closing-the-loop procedure that uses the developed framework to enable the identification of opportunities of improvement at the course and program levels.

- The deployment of the proposed framework within a two-cycle plan that led to a successful accreditation of a computer engineering program by ABET.

- Comparison with similar works and identification of future works.

The application of the proposed framework confirmed its effectiveness in achieving its purpose including assessing SOs, PIs, learning outcomes of courses, and evaluating student performance. Moreover, the framework application successfully identified opportunities of improvement, aided closing the assessment loop, and lead to a successful accreditation by ABET.

\section{Unified Framework}

The development of reliable and easy-to-deploy assessment plan is the main motivation for the proposed unified assessment and evaluation approach. The need for reliable assessment and evaluation is essential for the accurate identification of oppor- 
tunities for improvement and closing the assessment loop on solid, valid, and evidence-driven grounds. Moreover, the need for accurate assessment must not compromise the ease-of-deployment; otherwise, the applicability of the plan becomes challenging and can face major hurdles. The research objectives of the current investigation comprise the following: The SOs are the abilities that a student should possess at the time of graduation. The proof of attainment of SOs is a verification of the students' knowledge and a confirmation of their achievement of the intended learning objectives or standards set by a program. Furthermore, SO assessment and evaluation helps to identify areas of improvement in the curriculum and student learning. The proposed framework is built upon the concepts of OBA. In OBA, and upon the completion of the learning experience, a student is expected to attain the intended outcomes. Although surveying tools, such as exit surveys, can provide useful measurement of SO attainments, the focus of the presented methodology is on assessments carried out in courses. Assessments at the course level enjoy being accurate and strongly evident through exams and other direct tools. The learning outcomes identified at the courses level are then used as the building blocks of the framework. The proposed framework comprises the following levels:

1. Student outcomes (SOs)

2. Student outcome performance indicators (PIs)

3. Course learning outcomes (CLOs)

4. Assessment and evaluation components (AECs)

To facilitate the measurement of SOs, they are refined into a detailed set of PIs. The main motivation behind the expansion into PIs is to give a concrete meaning for every SO. The indicators are to adhere to the good principles of development including being specific, measurable, achievable, results-focused, and time-bounded (SMART).

The CLOs are the formal statements of what students are expected to learn in a course. The attainment of CLOs in a course can be measured in a variety of ways. For example, a qualitative rubric can be developed that can aid the assessment of attainment by the instructor of every student. The proposed framework adopts the use of a selection of AECs within a weighted-average formula to measure the attainment of every CLO per student. An AEC can be an exam, exam question, quiz, homework, project component, etc. AECs serve as the base of grading the student performance and calculating the attainment percentage score per CLO. The assessment scores per CLO enable the calculation of student percentage attainments in a course. At this point, one or more CLOs can map onto the PIs; here, the attainment scores of PIs are the weighted-average aggregation for those of the CLOs. The mappings among the AECs onto CLOs and onto PIs create a hierarchal framework that enables vertical assessments of SOs and horizontal evaluation of student performance in courses. Figure 1 depicts the hierarchy of the framework. The attainment and evaluation measurements are combined by a weighted average, given by $E=\sum_{k=1}^{K} \omega_{k} p\left(\mathrm{AEC}_{k}\right)$, where $E$ is the aggregate score, $p\left(\mathrm{AEC}_{k}\right)$ is the percentage score obtained for the $k^{\text {th }}$ component $\mathrm{AEC}_{k}$ and $\omega_{k}$ is the weight associated with the $k^{\text {th }}$ component $\mathrm{AEC}_{k}$ such 
that $0<\omega_{k}<1, k=1, \ldots, K$ and $\sum_{k=1}^{K} \omega_{k}=1$, where $K$ is the total number of AECs in a course.

\section{$4 \quad$ A Case-Study on Accrediting a Computer Engineering Program by ABET}

\subsection{Case-Study}

This paper studies the validity and the effectiveness of a framework for assessment of SOs. The framework enables a unified use of scores to obtain performance evaluations of students and attainment of CLOs, PIs, and SOs. The measurement of attainments for the PIs and SOs are taken in a set that ranges from sophomore to senior year courses and include courses that provide major design experiences including Capstone Design Projects (CDPs). The proposed framework stresses the need for triangulation of attainment scores based on complementary course characteristics.

The proposed framework provides simple and effective assessment of SOs. The simplicity comes from the limited set of courses where the assessment tools are deployed. The effectiveness is demonstrated through the successful accreditation of a computer engineering program by ABET. The study is carried out over two full assessment cycles, where each cycle is a single academic year (AY). The targeted academic years were the 2013-2014 and 2014-2015.

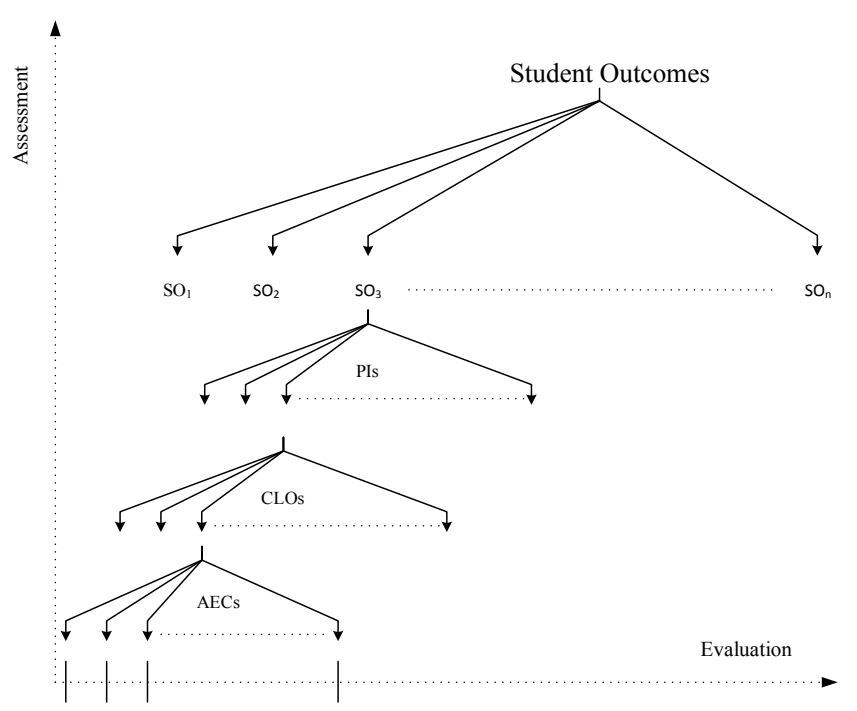

Fig. 1. The hierarchy of the unified framework for AE. Each SO is expanded into several PIs; assessment of the PI is carried out using careful mapping of a selected set of CLOs from a large bouquet of courses. Assessment of CLOs is carried out using a weighted average of selected AECs in a course. 


\subsection{Application in ABET Accreditation}

For the framework application, the initial set of computer engineering SOs provided by ABET is adopted. The SOs are 11 outcomes labeled (a) to (k). The SOs are refined into a set of 29 Performance Indicators (PIs; see Table 1).

\subsection{Course Learning Outcomes Level}

Courses comprise a large set of CLOs (See Table 2) that can support the assessment of PIs. The reliability of assessment is preserved even with the selection of a representative set of sampled courses. The application of the proposed framework samples from a set of courses that comprises digital logic design (DLD), computer organization and architecture (COA), electrical circuits (EC) and its lab (ECL), microcontrollers and interfacing (MI) and its lab (MIL), embedded system design (ESD), signals and systems (SS), and capstone design projects (CDPs). Table 1 presents a mapping among the CLOs and PIs to enable the measurement of attainment based on the measurements at the level of CLOs. The CLOs per course are welldesigned to provide clear mappings onto the indicators. For example, PI a.1 maps to the DLD course CLOs 1 and 2 with weights of $15 \%$ and $10 \%$.

Table 1. PIs, their weighted mapping to course CLOs, where the subscript indicates the CLP number and superscript indicates the weight, and the attainment scores over two assessment cycles over two AYs.

\begin{tabular}{|c|c|c|}
\hline \multirow[t]{2}{*}{ Performance Indicators } & \multicolumn{2}{|c|}{ Percentage Attainment Scores } \\
\hline & $2013-2014$ & $2014-2015$ \\
\hline $\begin{array}{l}\text { a1. Apply engineering mathematics to obtain solutions } \\
{\left[\mathrm{DLD}_{1}{ }^{15 \%}{ }_{2}{ }_{2}^{10 \%}, \mathbf{E C}_{1}{ }^{10 \%}{ }_{2}{ }_{2}^{15 \%},{ }_{3}^{10 \%}, \mathbf{S S}_{1}{ }^{10 \%}{ }_{2}{ }_{2}^{15 \%}, \mathbf{E E}_{7}{ }^{15 \%}\right]}\end{array}$ & $67 \%$ Developing & $59 \%$ Beginning \\
\hline $\begin{array}{l}\text { a2. Apply scientific and/or engineering principles to solve } \\
\text { engineering problems }\left[\mathbf{E C C}_{5}{ }^{15 \%},{ }_{6}{ }^{10 \%}, 7^{10 \%}, \mathbf{S S}_{3}{ }^{15 \%}, 4^{15 \%}, 5^{15 \%}\right. \\
\mathbf{C D P}^{20 \%} \text {, }\end{array}$ & $77 \%$ Competent & $77 \%$ Competent \\
\hline $\begin{array}{l}\text { b1. Use appropriate equipment and techniques for data col- } \\
\text { lection }\left[\mathbf{M I L}_{4}{ }^{10 \%},{ }_{5}^{10 \%},{ }_{6}^{10 \%},{ }_{7}^{10 \%},{ }_{8}^{10 \%}, \mathbf{E S D}_{5}{ }^{5 \%},{ }_{6}^{5 \%}, 7_{7}^{5 \%},{ }_{8}^{10 \%},\right. \\
\left.\mathbf{E C L}_{7}{ }^{10 \%}{ }_{8}^{10 \%}, \mathbf{C D P}^{5 \%}\right]\end{array}$ & $81 \%$ Competent & $78 \%$ Competent \\
\hline $\begin{array}{l}\text { b2. Analyze experimental data using appropriate tools } \\
{\left[\mathbf{C O A}_{2}{ }^{25 \%}, \mathbf{E C L}_{7}{ }^{25 \%},{ }_{8}{ }^{25 \%}, \mathbf{C D P}^{25 \%}\right]}\end{array}$ & $72 \%_{\text {Developing }}$ & $80 \%{ }_{\text {Competent }}$ \\
\hline 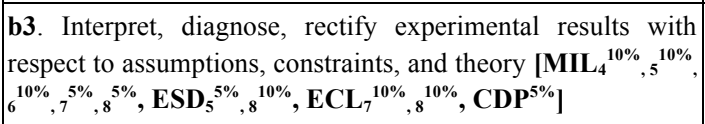 & $84 \% \%_{\text {Competent }}$ & $82 \%{ }_{\text {Competent }}$ \\
\hline $\begin{array}{l}\text { c1. Carry out a design procedure to meet desired needs } \\
{\left[\mathbf{M I}_{4}{ }^{30 \%}, \mathbf{E S D}_{5}{ }^{15 \%}{ }_{6}{ }^{15 \%}, \mathbf{C D P}{ }^{40 \%}\right]}\end{array}$ & $90 \%$ Accomplished & $77 \%$ Competent \\
\hline $\begin{array}{l}\text { c2. Designs a system within realistic constraints, such as, } \\
\text { specific implementation characteristics, economic, environ- } \\
\text { mental, social, political, ethical, health and safety, manufac- } \\
\text { turability, and sustainability }\left[\mathbf{M I}_{3}{ }^{15 \%}{ }_{5}{ }^{10 \%}{ }_{, 6}{ }^{10 \%}, \mathbf{E S D}_{5}{ }^{15 \%}{ }_{, 6}{ }^{10 \%},\right. \\
7^{10 \%}, \mathbf{C D P}^{30 \%} \text { ] }\end{array}$ & $79 \%$ Competent & $76 \%$ Competent \\
\hline
\end{tabular}


...Continue Table 1.

\begin{tabular}{|c|c|c|}
\hline Performance Indicators & Percentage $\mathbf{A}$ & Scores \\
\hline $\begin{array}{l}\text { d1. Share responsibilities with others on the team }\left[\mathbf{M I}_{8}{ }^{25 \%} \text {, }\right. \\
\left.\text { ESD }_{5}{ }^{25 \%}, \mathbf{C D P}^{50 \%}\right]\end{array}$ & $93 \%$ Accomplished & $65 \%$ Developing \\
\hline $\begin{array}{l}\text { d2. Participate in the discussions, developments, and imple- } \\
\text { mentations }\left[\mathbf{M I}_{\mathbf{8}}{ }^{25 \%}, \mathbf{E S D}_{5}{ }^{25 \%}, \mathbf{C D P}{ }^{50 \%}\right]\end{array}$ & $90 \%$ Competent & $85 \%_{\text {Accomplished }}$ \\
\hline d3. Participate in planning the team activities [CDP $\left.{ }^{\mathbf{1 0 0} \%}\right]$ & $77 \%$ Competent & $88 \%{ }_{\text {Competent }}$ \\
\hline $\begin{array}{l}\text { e1. Classify information to identify engineering problems } \\
{\left[\mathbf{E S D}_{5}{ }^{20 \%}{ }_{6}{ }^{20 \%}, \mathbf{E C}_{5}{ }^{10 \%}{ }_{6}{ }_{6}{ }^{30 \%}, \mathbf{C D P}^{20 \%}\right]}\end{array}$ & $89 \%$ Competent & $71 \%$ Developing \\
\hline $\begin{array}{l}\text { e2. Develop appropriate models to formulate solutions } \\
{\left[\mathbf{E S D}_{5}{ }^{15 \%}{ }_{6}{ }^{15 \%}, \mathbf{S S}_{5}{ }^{40 \%}, \mathbf{C D P}^{30 \%}\right]}\end{array}$ & $81 \%$ Competent & $71 \%$ Developing \\
\hline $\begin{array}{l}\text { e3. Use analytical, numerical, and/or experimental methods } \\
\text { to obtain solutions }\left[\mathbf{C O A}_{2}{ }^{10 \%},{ }_{3}^{5 \%},{ }_{9}{ }^{0 \%}, \mathbf{M I L}_{3}{ }^{15 \%} \text {, EC }{ }_{5}^{15 \%} \text {, }\right. \\
\left.{ }_{11}{ }^{10 \%}, \mathbf{E C L}_{2}{ }^{5 \%},{ }_{3}{ }^{5 \%},{ }_{4}{ }^{5 \%},{ }_{5}^{5 \%},{ }_{7}{ }^{5 \%}, \mathbf{C D P}^{20 \%}\right]\end{array}$ & $81 \%{ }_{\text {Competent }}$ & $86 \%$ Competent \\
\hline $\begin{array}{l}\text { f1. Evaluate ethical issues (such as safety, intellectual prop- } \\
\text { erty, reporting data, etc.) that may occur in professional } \\
\text { practice using professional codes of ethics } \text { [MI }_{\mathbf{8}}{ }^{\mathbf{1 0} \%} \text {, } \\
\mathbf{E S D}_{\mathbf{5}}{ }^{\mathbf{1 0}}, \mathbf{C D P}^{\mathbf{8 0} \%} \text { ] }\end{array}$ & $85 \%$ Competent & $73 \%_{\text {Developing }}$ \\
\hline $\begin{array}{l}\text { f2. Demonstrate professional and ethical responsibility, such } \\
\text { as, health and safety, intellectual property, reporting data, } \\
\text { etc. }\left[\mathbf{M I}_{\mathbf{8}}{ }^{\mathbf{1 0 \%}}, \mathbf{E S D}_{\mathbf{5}}{ }^{\mathbf{1 0 \%}}, \mathbf{E C}_{\mathbf{1}}{ }^{\mathbf{1 0 \%}}, \mathbf{C} \mathbf{D P}^{\mathbf{7 0} \%}\right]\end{array}$ & $84 \%$ Competent & $76 \%$ Competent \\
\hline $\begin{array}{l}\text { f3. Communicate in a professional manner } \text { [ESD }_{5}{ }^{20 \%} \text {, } \\
\text { CDP }{ }^{80 \%} \text { ] }\end{array}$ & $85 \% \%_{\text {Accomplished }}$ & $73 \%$ Developing \\
\hline $\begin{array}{l}\text { g1. Write technical reports using appropriate formats and } \\
\text { grammar with discipline-specific conventions including } \\
\text { citations }\left[\mathbf{M I}_{\mathbf{8}}{ }^{\mathbf{1 5 \%}}, \mathbf{E S D}_{\mathbf{5}}{ }^{\mathbf{1 5 \%}}{ }_{\mathbf{8}}^{\mathbf{1 0} \%}, \mathbf{E C L}_{\mathbf{9}}{ }^{\mathbf{3 0} \%}, \mathbf{C D P}^{\mathbf{3 0} \%}\right]\end{array}$ & $76 \%$ Competent & $81 \%$ Competent \\
\hline $\begin{array}{l}\text { g2. Deliver well-organized, well-explained, and well-timed } \\
\text { oral presentations }\left[\mathbf{C O A}_{\mathbf{1}}{ }^{\mathbf{2 0} \%}, \mathbf{M I}_{\mathbf{8}}{ }^{20 \%}, \mathbf{C D P}{ }^{60 \%}\right]\end{array}$ & $85 \%$ Accomplished & $81 \%$ Competent \\
\hline $\begin{array}{l}\text { h1. Demonstrate awareness of the impact of engineering } \\
\text { solutions in a global, economic, environmental, and/or } \\
\text { societal context }\left[\mathbf{C O A}_{\mathbf{1}}{ }^{\mathbf{1 5 \%}}, \mathbf{E E}_{\mathbf{1}}{ }^{\mathbf{1 5 \%}}{ }_{\mathbf{2}}{ }^{\mathbf{1 5 \%}}, \mathbf{C D P}^{\mathbf{5 5} \%}\right]\end{array}$ & $89 \%$ Accomplished & $80 \%$ Competent \\
\hline $\begin{array}{l}\text { h2. Evaluate engineering solutions that consider global, } \\
\text { economic, environmental, and/or societal factors }\left[\mathbf{E E}_{\mathbf{1}}{ }^{15 \%} \text {, }\right. \\
\left.{ }_{2}^{15 \%},{ }_{4}^{20 \%}, \mathbf{C D P}^{50 \%}\right]\end{array}$ & $85 \%_{\text {Accomplished }}$ & $78 \%$ Competent \\
\hline $\begin{array}{l}\text { i1. Learn and apply new material not taught in class }\left[\mathbf{M I}_{\mathbf{8}}{ }^{10 \%} \text {, }\right. \\
\left.\mathbf{E S D}_{\mathbf{5}}{ }^{25 \%},{ }_{8}{ }^{25 \%}, \mathbf{C D P}^{40 \%}\right]\end{array}$ & $91 \% \%_{\text {Accomplished }}$ & $89 \%$ Accomplished \\
\hline $\begin{array}{l}\text { i2. Identify the knowledge and skills needed at the beginning } \\
\text { of a project and develop a plan for acquiring the missing } \\
\text { knowledge and skills [CDP }{ }^{100 \%} \text { ] }\end{array}$ & $91 \%$ Accomplished & $94 \%$ Accomplished \\
\hline $\begin{array}{l}\text { i3. Evaluate results and analyze information obtained using } \\
\text { new techniques and tools not taught in class }\left[\mathbf{C O A}_{\mathbf{2}}{ }^{15 \%}{ }_{4}{ }^{15 \%} \text {, }\right. \\
\left.{ }_{6}{ }^{15 \%}, \mathbf{M I}_{\mathbf{8}}{ }^{15 \%}, \mathbf{E S D}_{5}{ }^{5 \%}{ }_{8}{ }^{15 \%}, \mathbf{C D P}^{20 \%}\right]\end{array}$ & $84 \% \%_{\text {Competent }}$ & $81 \% \%_{\text {Competent }}$ \\
\hline $\begin{array}{l}\text { j1. Describe the impact of contemporary issues on society, } \\
\text { such as, environmental, global, economic, emerging technol- } \\
\text { ogies, etc. }\left[\mathbf{C O A} \mathbf{A}_{\mathbf{1}}{ }^{\mathbf{2 0} \%}, \mathbf{M I}_{\mathbf{5}}{ }^{30 \%}, \mathbf{S S}_{\mathbf{6}}{ }^{\mathbf{3 0} \%}, \mathbf{C D P}{ }^{\mathbf{2 0} \%}\right]\end{array}$ & $83 \%$ Competent & $84 \%$ Competent \\
\hline $\begin{array}{l}\text { j2. Incorporate contemporary issues, such as, economic, } \\
\text { environmental, etc. in projects and papers } \\
{\left[\mathbf{C O A} \mathbf{A}_{\mathbf{1}}{ }^{\mathbf{3 0} \%}, \mathbf{C D P}^{\mathbf{7 0 \%}}\right]}\end{array}$ & $98 \%$ Accomplished & $93 \%$ Accomplished \\
\hline
\end{tabular}


...Continue Table 1.

\begin{tabular}{|c|c|c|}
\hline Performance Indicators & \multicolumn{2}{|c|}{ Percentage Attainment Scores } \\
\hline $\begin{array}{l}\text { k1. Use engineering equipment and instruments } \\
{\left[\mathbf{M I L}_{1}{ }^{5 \%},{ }_{2}^{5 \%},{ }_{3}^{5 \%},{ }_{4}{ }^{5 \%},{ }_{5}^{5 \%},{ }_{6}^{5 \%},{ }_{7}^{5 \%},{ }_{8}{ }^{5 \%}, \mathbf{E S D}_{5}{ }^{5 \%},{ }_{8}{ }^{5 \%}, \mathbf{E C L}_{7}{ }^{15 \%},\right.} \\
\left.{ }_{8}{ }^{15 \%}, \mathbf{C D P}^{20 \%}\right]\end{array}$ & $76 \%_{\text {Competent }}$ & $86 \%$ Accomplished \\
\hline $\begin{array}{l}\text { k2. Utilize programmable devices, such as, microcontrollers } \\
\text { and PLDs }\left[\mathbf{M I L}_{3}{ }^{30 \%}, \mathbf{E S D}_{\mathbf{5}}{ }^{\mathbf{2 0} \%},{ }_{\mathbf{8}}{ }^{\mathbf{2 0} \%}, \mathbf{C D P}^{\mathbf{3 0} \%} \text { ] }\right.\end{array}$ & $91 \%_{\text {Accomplished }}$ & $86 \%$ Accomplished \\
\hline $\begin{array}{l}\text { k3. Use computer-aided design and analysis software tools } \\
\text { for computer engineering applications }\left[\mathbf{C O A}_{\mathbf{2}}{ }^{10 \%}, \mathbf{4}^{\mathbf{1 0 \%}},{ }_{\mathbf{6}}{ }^{10 \%} \text {, }\right. \\
\left.\mathbf{M I L}_{\mathbf{1}}{ }^{\mathbf{2 0} \%}, \mathbf{E S D}_{\mathbf{8}}{ }^{{ }^{20} \%}, \mathbf{E C L}_{\mathbf{8}}{ }^{20 \%}, \mathbf{C D P}{ }^{10 \%}\right]\end{array}$ & $82 \%$ Competent & $86 \%$ Accomplished \\
\hline $\begin{array}{l}\text { k4. Build prototypes that meet design specifications } \\
{\left[\mathbf{M I}_{\mathbf{8}}{ }^{20 \%}, \mathbf{M I L}_{5}{ }^{10 \%}{ }_{6}{ }^{10 \%},{ }_{7}^{10 \%}, \mathbf{E S D}_{5}{ }^{25 \%}, \mathbf{C D P}^{25 \%}\right]}\end{array}$ & $77 \%$ Competent & $76 \%_{\text {Competent }}$ \\
\hline
\end{tabular}

Table 2. The developed set of course learning outcomes (CLOs) per course; only CLOs with a high-emphasis $(\mathrm{H})$ mapping to the PIs are shown.

Digital Logic Design (DLD)

(1) Apply number system conversions, typically related to binary system

(2) Simplify Boolean expressions using basic theorems and properties of Boolean Algebra

Computer Organization and Architecture (COA)

(1) Demonstrate an understanding of the basic organization and architecture of modern computer systems

(2) Analyze computer system performance

(3) Demonstrate an understanding of how computer programs are organized, stored, and executed at the machine level

(4) Write basic assembly language programs

(6) Analyze an instruction-set architecture and propose a suitable datapath and control unit implementations

(9) Demonstrate an understanding of the input/output mechanisms used to connect computers to their external environments

\section{Microprocessors and Interfacing (MI)}

(3) Design microcontroller applications

(4) Develop microcontroller applications

(5) Learn both HW and SW aspects of integrating digital devices (such as memory and I/O interfaces) into microcontroller-based systems

(6) Learn the operating principles of common microcontroller peripherals such as UARTs, timers, and $\mathrm{A} / \mathrm{D}$ and $\mathrm{D} / \mathrm{A}$ converters

(7) Use microcontrollers to implement projects

Microprocessors and Interfacing Lab (MIL)

(1) Use MPLAB to successfully write, debug, trace, and execute assembly programs

(2) Write assembly language programs

(3) Experiment with the available PIC microcontroller hardware to run various microcontroller applications

(4) Implement input interface applications including switches, push buttons, and keypads

(5) Implement output interface applications including 7-segment and LCD displays

(6) Implement motor control applications including DC and stepper motors control

(7) Implement time-sensitive applications using timers, interrupts, and clocks

(8) Implement data conversion applications using ADCs 
...Continue Table 2.

\section{Embedded Systems Design (ESD)}

(5) Design and implement Specific Purpuse Processors (Datapath, FSM, FSMD, and controller)

(6) Design and implement Application-Specific Instruction-set Processors (Instructions, Format, Datapath, FSM, FSMD, and controller)

(7) Use different memory arrangements in embedded systems

(8) Write VHDL programs with advanced features

\section{Electric Circuits (EC)}

(1) Apply algebraic techniques to solve simultaneous equations

(2) Solve linear differential equations

(3) Use complex numbers

(5) Apply different circuit analysis techniques to solve electric circuits, such as KVL, KCL, node voltages, mesh currents etc.

(6) Choose the preferred analytical approach for solving a particular circuit

(7) Determine the response of electric circuits to both DC and AC inputs

(11) Obtain both the transient and steady state responses of RC, RL, and RLC circuits

\section{Electric Circuits Laboratory (ECL)}

(2) Verify experimental results using Multisim to simulate electric circuits' behavior

(3) Apply Ohm's law and Kirchhoff's laws in analyzing, designing, and implementing simple electrical circuits

(4) Analyze complex circuits by applying different measurements and testing techniques

(5) Determine the maximum power transfer conditions via applying the Thévenin and Norton equivalents

(7) Analyze RL, RC and RLC circuits to find their significant parameters

(8) Experiment with sinusoidal AC applications

(9) Write reports according to the standard technical writing requirements

\section{Signals and Systems (SS)}

(1) Demonstrate an understanding of the fundamentals of signals, systems and their classification using real-world examples

(2) Demonstrate an understanding of the role of convolution in the time-domain analysis of LTI systems (3) Apply frequency domain transformation techniques (Laplace, Fourier, $Z$ etc.) for the analysis of signals and systems

(4) Demonstrate an understanding of the sampling of continuous-time signals and the implication of the Nyquist sampling theorem

(5) Design frequency selective filters

(6) Apply signals and systems theory towards multimedia processing, communication and pattern recognition

Engineering Economics (EE)

(1) Demonstrate an understanding of the principles and basic concepts of engineering economy

(2) Explain the fundamental concepts of engineering economy as related to Electrical and Computer Engineering

(7) Apply probability and statistics to analyze the risk in case-studies related to Electrical and Computer Engineering

Electrical Circuits (EC) is a core course in almost all computer engineering programs. The proposed course has 11 CLOs; the first three are dedicated to measure and assess applied mathematical capabilities. The remaining nine follow the structure outlined in the course textbook [12]. The CLOs of the EC course map to ABET SOs with three levels of emphasis (See Table 3). An SO mapping emphasis is either high $(\mathrm{H})$, medium $(\mathrm{M})$, or low (L); the emphasis depends on the extent of coverage of a $\mathrm{CLO}$ in the course materials in relation to an SO. 
In the current investigation, a variety of assessment components are employed including Course Work (CW) that comprise seven homework sets (HW) and six inclass quizzes (QZ). In addition, assessment components include Design Project (DP), Midterm Exam (ME), ME Question (MEQ), a Final Exam (FE), and FE Question (FEQ). The evaluation of student performance is calculated using a weighted average formula to produce the student's total percentage score in the course. The attainment of CLOs is calculated based on the scores of specific AECs. The adopted mapping of AECs onto CLOs and the assigned weights (Ws) are shown in Table 4. The proposed approach is unified in the sense that it provides attainment scores for each CLO and SO, besides, evaluating the performance of students. A sample FEQ is shown in Figure 2; the question is MEQ-6 that maps explicitly onto CLOs 1, 3 and 11, and implicitly onto CLOs 4, 6, and 7. At this point, the attainment of an SO is calculated as the average of attainments of all mapped CLOs only with high $(\mathrm{H})$. An alternate calculation of the attainment that employs a weighted average formula based on all the three emphasis levels $\mathrm{H}, \mathrm{M}$, and $\mathrm{L}$ is also possible. Based on the attainment percentage scores, a ranking is assigned for each CLO per the following rubric:

- Beginning: Below basic achievement, percentage attainment is below $65 \%$

- Developing: Basic achievement, percentage attainment is between $65 \%$ and $75 \%$

- Competent: Satisfactory achievement, score between $75 \%$ and $85 \%$

- Accomplished: Mastery of a learning outcome, score above $85 \%$

Table 3. Mapping of the Electric Circuits (EC) CLOs (1 through 11) to the SOs (a through k) with the level of emphasis.

\begin{tabular}{|c|c|c|c|c|c|c|c|c|c|c|c|}
\hline & $\mathbf{a}$ & b & c & d & e & $\mathbf{F}$ & $\mathbf{g}$ & $\mathbf{h}$ & $\mathbf{i}$ & $\mathbf{j}$ & $\mathbf{k}$ \\
\hline 1 & $\mathrm{H}$ & & & & $\mathrm{M}$ & & & & & & \\
\hline 2 & $\mathrm{H}$ & & & & $\mathrm{M}$ & & & & & & \\
\hline 3 & $\mathrm{H}$ & & & & $\mathrm{M}$ & & & & & & \\
\hline 4 & $\mathrm{M}$ & & & & $\mathrm{M}$ & & & & & & \\
\hline 5 & $\mathrm{M}$ & & $\mathrm{M}$ & & $\mathrm{H}$ & & & & & & $\mathrm{H}$ \\
\hline 6 & $\mathrm{M}$ & & $\mathrm{H}$ & & $\mathrm{H}$ & & & & & & $\mathrm{H}$ \\
\hline 7 & $\mathrm{H}$ & & & & $\mathrm{L}$ & & & & & & $\mathrm{L}$ \\
\hline 8 & $\mathrm{~L}$ & & $\mathrm{M}$ & & $\mathrm{H}$ & & & & & & $\mathrm{H}$ \\
\hline 9 & $\mathrm{M}$ & & $\mathrm{H}$ & & $\mathrm{H}$ & & & & $\mathrm{L}$ & & $\mathrm{H}$ \\
\hline 10 & $\mathrm{M}$ & & $\mathrm{M}$ & & $\mathrm{H}$ & & & & $\mathrm{M}$ & & $\mathrm{M}$ \\
\hline 11 & $\mathrm{H}$ & & & & $\mathrm{L}$ & & & & & & $\mathrm{L}$ \\
\hline
\end{tabular}


Table 4. Matrix of weighted Assessment and Evaluation Components for all clos of the Electric Circuits (EC) course as presented in Table 3.

\begin{tabular}{|c|c|c|c|c|c|c|c|c|}
\hline \multirow{2}{*}{ CLO } & \multicolumn{2}{|c|}{ AC \#1 } & \multicolumn{2}{|c|}{ AC\#2 } & \multicolumn{2}{|c|}{ AC\#3 } & \multicolumn{2}{|c|}{ AC\#4 } \\
\hline & Cs & W\% & Cs & W\% & Cs & W\% & Cs & W\% \\
\hline 1 & HW 2-4 & 20 & QZ 1-3 & 10 & ME & 40 & FE O $1 / 2 / 6$ & 30 \\
\hline 2 & HW 7,8 & 30 & QZ 5,6 & 20 & PR & 15 & FE Q 4,5 & 35 \\
\hline 3 & HW 9 & 60 & $\mathrm{DP}$ & 10 & FE Q 6 & 30 & & \\
\hline 4 & $\mathrm{CW}$ & 30 & DP & 10 & $\mathrm{ME}$ & 35 & $\mathrm{FE}$ & 25 \\
\hline 5 & $\mathrm{CW}$ & 40 & ME & 60 & & & & \\
\hline 6 & HW 4,5,7-9 & 30 & QZ 3-6 & 30 & ME & 20 & $\mathrm{FE}$ & 20 \\
\hline 7 & $\mathrm{CW}$ & 40 & DP & 30 & FE & 30 & & \\
\hline 8 & HW & 40 & DP & 60 & & & & \\
\hline 9 & ME Qs 3,5 & 20 & QZ 4 & 10 & DP & 50 & FE Q 1 & 20 \\
\hline 10 & DP & 100 & & & & & & \\
\hline 11 & HW 7-9 & 25 & QZ 5,6 & 25 & DP & 25 & FE Q 4-6 & 25 \\
\hline
\end{tabular}

Q6. For the circuit, shown in figure, $v_{g}=12 \cos \left(\omega t-60^{\circ}\right) \mathrm{V}$, where $\omega=$ 2,000 rad/s. Find:

i. $\quad$ the impedance of both $L$ and $C$

ii. a time-domain steady state expression for $i_{g}$

iii. a time-domain steady state expression for $v_{o}$, and

iv. the time delay between $v_{o}$ and the $v_{g}$ (indicate lag/lead)

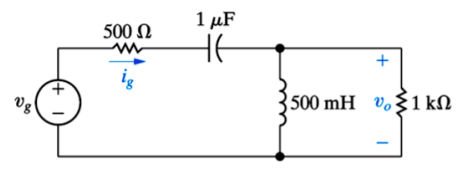

Fig. 2. Sample MEQ-6 component that maps onto CLOs 1, 3, and 11.

\subsection{Capstone Design Project Courses}

In the proposed assessment methodology, CDPs are selected as one of the main components of the set of courses of measurements. The CDP setup, assessment, and evaluation follow the structure of the tool presented in [13]. The adopted methodology is unified in the sense that it provides attainment scores for CLOs, PIs and SOs, in addition to evaluating student performance.

As per the adopted setup, CDPs are scheduled over a period of two regular semesters. The pre-requisite for the CDP is a senior design experience provided in the courses on Microprocessors, Microcontrollers and Interfacing, and Embedded System Design. The pre-requisite courses are equipped with extensive practical laboratory components. The following assessment tools are used to assess the CDPs and the performance of each student:

- CDP proposal (at the beginning of Semester I)

- Periodic meetings with the CDP supervisor 
- Progress reports (in the middle of Semesters I and II)

- Oral examination of individual students by the supervisor (at the end of Semesters I and II)

- An essay related to integrity, values, and impact of engineering solutions (at the end of Semester II)

- CDP presentation, demonstration, and committee exam

The assessment of CDPs is based upon the following criteria:
A. Content
B. Integrity, values, and impact of engineering solutions
C. Project management and teamwork skills
D. Written communication
E. Presentation and oral communication

The criteria, key indicators, and percentage weight assignments are shown in Table 5. Table 6 shows the mapping among of the CDP evaluation criteria and PIs SOs (a) through $(\mathrm{k})$. As the mappings are many-to-many; a weighted calculation is used to quantify the assessment for SOs. The assessment tool including the complete set of analytic rubrics is presented in detail in [13].

Table 5. Developed criteria, key indicators, and weights per criterion and indicators [13].

\section{A. Content}

(Total \%55, Supervisor \%35 and Examination Committee \%20)

1. Literature review: summarizes, compares and evaluates various concepts, research findings and current theories and models in core content areas of computer and electrical engineering $(10 \%)$

2. Identify engineering principles and techniques that are relevant to the project and apply them within specific problem domain $(5 \%)$

3. Novelty and the adequacy of the design approach $(10 \%)$

4. Alternative designs (10\%)

5. Identification, mastering, and use of hardware/software tools (5\%)

6. Robustness of conducting, analyzing, testing and interpreting experimental results (5\%)

7. Further improvements $(10 \%)$

B. Integrity, values, and impact of engineering solutions

(\%5, Supervisor and Examination Committee Members)

1. Clear understanding of and adherence to scientific and professional ethics. (2\%)

2. Aware of the impact of engineering solutions in a global, economic, environmental, and/or societal context (1\%)

3. Evaluate engineering solutions that consider global, economic, environmental, and/or societal factors $(2 \%)$

C. Project Management and Teamwork skills

(\%10, Supervisor)

1. Work individually, or as part of team where appropriate, to formulate, analyze, design, and implement a significant engineering project (3\%)

2. Contribution to the team project/work $(3 \%)$

3. Taking responsibility $(4 \%)$

\section{Written Communication} (\%10, Supervisor and Examination Committee Members)

1. Organization and logic (4\%)

2. Writing style (word choice, grammar and sentence structure) $(4 \%)$

3. Use of References $(2 \%)$ 
...Continue Table 5.

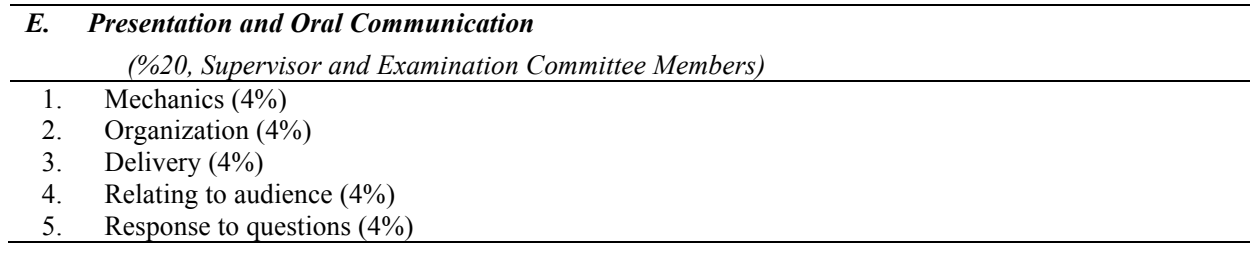

Table 6. Mapping among CDP evaluation criteria and PIs.

\begin{tabular}{|c|c|c|c|}
\hline $\mathbf{P}$ & CDP Indi- & $\mathbf{P}$ & CDP Indica- \\
\hline $\mathbf{a}$ & $\mathrm{A} 2$ & $\mathbf{f}$ & B1 \\
\hline b & $\mathrm{A} 5, \mathrm{~A} 6$ & g & D1, D2, D3 \\
\hline $\mathbf{b}$ & $\mathrm{A} 5, \mathrm{~A} 6$ & g & E1, E2, E3, \\
\hline b & $\mathrm{A} 5, \mathrm{~A} 6, \mathrm{~A} 7$ & h & B2 \\
\hline c & $\mathrm{A} 3, \mathrm{~A} 4$ & h & B3 \\
\hline c & $\mathrm{A} 3, \mathrm{~A} 4, \mathrm{~A} 7$ & $\mathbf{i}$ & $\mathrm{A} 2, \mathrm{~A} 5$ \\
\hline d & $\mathrm{C} 3$ & $\mathbf{i}$ & $\mathrm{A} 2, \mathrm{~A} 5$ \\
\hline d & $\mathrm{C} 2$ & $\mathbf{i}$ & $\mathrm{A} 2, \mathrm{~A} 5$ \\
\hline d & $\mathrm{C} 1$ & $\mathbf{j}$ & A1 \\
\hline e & $\mathrm{A} 1, \mathrm{~A} 2$ & $\mathbf{j}$ & $\mathrm{A} 2$ \\
\hline e & $\mathrm{A} 2, \mathrm{~A} 4$ & $\mathbf{k}$ & $\mathrm{A} 2, \mathrm{~A} 5$ \\
\hline e & $\mathrm{A} 2, \mathrm{~A} 4$ & $\mathbf{k}$ & A2, A5 \\
\hline $\mathbf{f}$ & B1 & $\mathbf{k}$ & $\mathrm{A} 2, \mathrm{~A} 5$ \\
\hline $\mathbf{f}$ & B1 & $\mathbf{k}$ & $\mathrm{A} 5, \mathrm{~A} 6$ \\
\hline
\end{tabular}

\subsection{Deployment and Closing the Loop}

The proposed framework requires one course assessment form (CAF) for each course from the selected set of sampled courses. The CAF is focused on the calculation of attainment scores of CLOs as shown in Table 4. The CAFs are initiated by the course instructor(s) and submitted for further review at the program level. During this cycle, proofing is done to make sure that the data, statistics, comments and conclusions are consistent. In addition, supporting evidence is attached to the CAFs, including results to ensure the quality of the assessment process. The review at the program level places great value on the direct assessment of learning outcomes as collected and analyzed using the course form and CDP assessments. The assessment results, collected using the forms, are combined to calculate an attainment score in percent for every PI. Opportunities of improvement are identified at the course levels through the CLO attainment scores. Opportunities for improvement at the program level are identified using the PIs and SOs attainment scores. Indeed, other assessment tools can be used in assessment for triangulation and wider coverage; such tools include different types of surveys and recommendations from faculty, staff, and industrial and student advisory boards. 


\section{$5 \quad$ A Case-Study on Accrediting a Computer Engineering Program by ABET}

\subsection{Results}

Table 7 shows the CLO attainment results for the EC course as sampled over the two assessment cycles of the AY 2013 - 2014 and 2014 - 2015. The attainment scores of PIs are calculated based on the CLO scores; PI scores are shown in Table 1. The attainment scores of SOs are calculated as the average of PIs (See Table 8). The ranking of all attainment scores follows the same rubric of the CLOs.

\subsection{General Evaluation}

Many benefits are noted for the proposed framework. The framework addresses the need to identify a limited pool of courses from different seniority levels to obtain accurate assessment results. The selected manageable set of sampled courses aims to facilitate the assessment process including data collection, while maintaining effectiveness. The many-to-many mapping among courses, PIs, and SOs enables the triangulation of assessment results from different extensive sources of measurements. The conceptual base of the framework is refined into a clear measurement structure that measures both SO attainments and student performance. The framework can easily be adopted by other programs and disciplines without changing the statistics or the measurement structure. To close the assessment loop, evaluation can lead to identification of opportunities of improvement at the course level, using CAFs, or at the PI and SO levels. CLO, PI, or SO scores that are below the desired competency level is considered an opportunity of improvement. Identified low scores at the PI and SO levels trigger an investigative backtracking procedure to check relevant CLOs, whether within or outside the pool of sampled courses, to propose improvements. The framework was deployed within a two-cycle assessment plan. The case-study provides the opportunity for deep reasoning and analysis of the proposed framework. The application of the framework successfully led to accrediting the computer engineering program at the American University of Kuwait by ABET in August 2016 with the AY $2021-2022$ as the expected year of next evaluation [14]. The self-study report of the computer engineering program that adopted the proposed framework was featured, as exemplary, during ABET Symposium 2016 [15].

The adopted CDP measurement tool, from [13], clearly identifies the evaluations at the level of the team and individuals and enables adequate distinction for the assessment of students. The adopted CDP tool unifies the evaluation of project and course qualities and the assessment of attainment of outcomes.

\subsection{Challenges and Limitations}

The aim of the developed framework is to endorse the principles of reliable, thorough, accurate, easy-to-deploy, and unified assessment and evaluation. The successful 
application of the framework faces several challenges including the reliance on the commitment of assessors to design AECs, to thoroughly review the course material, and to provide concrete evidences. Data collection, result aggregation, identification of opportunities for improvement, besides sorting, filing, organization, and ease of access of data require careful setup and use of records keepings and software tools support.

A couple of limitations are identified for the proposed framework and it sets the ground for future work. A multi-site study can provide increased confidence in the obtained results and enables wider considerations. The duration of the case-study is limited to two assessment cycles over two academic years. The duration can be extended to provide a deeper analysis of the result trends. Indeed, the study is for a program with specific curriculum and course setups. Similar program setups must be made to successfully adopt the framework.

\subsection{Closely Related Work}

A variety of frameworks are developed to measure the attainment level of the SOs. Designing of curricula, course assessment forms, performance indicators, and reports for continuous improvements play an important role in this process. Many successful case studies were presented to exemplify these frameworks using both direct and indirect methods. Deciding on which courses should contribute to assess a certain SO and what assessment tools to be used is usually the first and most important step. In [16], it is argued that using course work for assessment is very time consuming for the faculty involved and for any outside assessment coordinator; consequently, only comprehensive final exams are used. The proposed exams were locally designed by a special committee and go through a continuous cycle of refining and improvements. Many other institution, especially in the US, use standardized tests, such as SAT, GRE, and MFAT; although this kind of assessment establishes a unified ground for international comparisons, it sometimes lacks the ability to provide the necessary level of detail required for adequate outcomes assessment [17]. Depending on just the grade average can be used to assess SOs, as illustrated in [18], only class averages are used as assessment with a reference threshold score of a single practical assignment. Using dedicated assessment tools that are independent from evaluation, such as essays, tailored assessment exams, and E-portfolios are used in [19]; these tools are often combined with grading rubrics to measure the degree of competency, required for different SOs; they can be also aggregated with grades to better assess the curricula. Other frameworks that depend on national competitions and exams, capstones and senior design courses, among other methods for measuring SOs were also reported in the literature [20-22].

\section{Conclusion}

The development of reliable, effective-in-application, and easy-to-deploy assessment plans are a world-wide interest of academic programs. This paper studies the 
validity and the effectiveness of a framework for assessment of SOs. The framework enables a unified use of scores to obtain performance evaluations of students and attainment of CLOs, PIs, and SOs. The framework is deployed within two assessment cycles each of one AY. The framework made a robust tool and the results led to successful identification of opportunities for improvement, closing the assessment loop, and accreditation by ABET of a Computer engineering program. The deployment results identified improvements for CLOs 2, 3, and 9 in the EC course during the AY $2013-2014$ and proved the major enhancement in the attainment of CLOs 2 and 9 during the AY $2014-2015$. The results highlighted the main need for improvement in attaining indicators a1, d1, e1, e2, f1, f3, and accordingly $\mathrm{SO}(\mathrm{a})$ and $\mathrm{SO}(\mathrm{f})$ with ranks of Beginning and/or Developing. Future work includes the development of additional software tools that facilitate the deployment of the framework. Future work also includes carrying out a multi-site study over a longer duration that can provide increased confidence in the obtained results and enables wider considerations.

Table 7. Attainment scores for the CLOs of the Electric Circuits (EC) course over two assessment cycles.

\begin{tabular}{|c|l|l|}
\hline $\mathbf{C L O}$ & $\mathbf{A Y} \mathbf{1 3}-\mathbf{1 4}$ & $\mathbf{A Y} \mathbf{1 4}-\mathbf{1 5}$ \\
\hline $\mathbf{1}$ & $82 \%_{\text {Competent }}$ & $80 \%_{\text {Competent }}$ \\
\hline $\mathbf{2}$ & $63 \%_{\text {Beginning }}$ & $80 \%_{\text {Competent }}$ \\
\hline $\mathbf{3}$ & $69 \%_{\text {Developing }}$ & $64 \%_{\text {Beginning }}$ \\
\hline $\mathbf{4}$ & $82 \%_{\text {Competent }}$ & $84 \%_{\text {Competent }}$ \\
\hline $\mathbf{5}$ & $95 \%_{\text {Accomplished }}$ & $84 \%_{\text {Competent }}$ \\
\hline $\mathbf{6}$ & $77 \%_{\text {Competent }}$ & $76 \%_{\text {Developing }}$ \\
\hline $\mathbf{7}$ & $76 \%_{\text {Competent }}$ & $88 \%_{\text {Accomplished }}$ \\
\hline $\mathbf{8}$ & $88 \%_{\text {Accomplished }}$ & $100 \%_{\text {Accomplished }}$ \\
\hline $\mathbf{9}$ & $65 \%_{\text {Developing }}$ & $76 \%_{\text {Accomplished }}$ \\
\hline $\mathbf{1 0}$ & $88 \%_{\text {Accomplished }}$ & $96 \%_{\text {Accomplished }}$ \\
\hline $\mathbf{1 1}$ & $71 \%_{\text {Developing }}$ & $84 \%_{\text {Competent }}$ \\
\hline
\end{tabular}


Table 8. Attainment scores for the SOs over two assessment cycles.

\begin{tabular}{|c|c|c|}
\hline SO & AY $13-14$ & AY $14-15$ \\
\hline $\mathbf{a}$ & $72 \%$ Developing & $68 \%$ Developing \\
\hline $\mathbf{b}$ & $79 \%{ }_{\text {Competent }}$ & $80 \%{ }_{\text {Competent }}$ \\
\hline c & $84.5 \%{ }_{\text {Competent }}$ & $76.5 \%_{\text {Competent }}$ \\
\hline d & $86.6 \%$ Accomplished & $79.33 \%$ Competent \\
\hline $\mathbf{e}$ & $83.6 \%{ }_{\text {Competent }}$ & $76 \%{ }_{\text {Competent }}$ \\
\hline f & $84.6 \%{ }_{\text {Competent }}$ & $74 \%$ Developing \\
\hline $\mathbf{g}$ & $80.5 \%$ Competent & $81 \%{ }_{\text {Competent }}$ \\
\hline h & $87 \%_{\text {Accomplished }}$ & $79 \%{ }_{\text {Competent }}$ \\
\hline $\mathbf{i}$ & $88.6 \%_{\text {Accomplished }}$ & $88 \%_{\text {Accomplished }}$ \\
\hline j & $90.5 \%_{\text {Accomplished }}$ & $88.5 \%{ }_{\text {Accomplished }}$ \\
\hline $\mathbf{k}$ & $81.5 \%$ Competent & $83.5 \%$ Competent \\
\hline
\end{tabular}

\section{$7 \quad$ References}

[1] Li Jin (2010). A Research on the Quality Assessment in Higher Education Institutions, in Proc. E-Product E-Service and E-Entertainment Conf. Henan, China, pp. 1-4.

[2] H. Braun, A.Kanjee, E.Bettinger, and M.Kremer (2006). Improving Education Through Assessment, Innovation, and Evaluation, The American Academy of Arts and Sciences.

[3] L. Suskie (2004). Assessing student learning: A common sense guide, MA: Anker Publishing Company, Inc., Bolton.

[4] M. F.Wyne, Ensure program quality: Assessment a necessity, in Proc. IEEE EDUCON Conf., Madrid, Spain, 2010 pp. 1621-1630. https://doi.org/10.1109/EDUCON. 2010.5492396

[5] J. E. Froyd, P. C. Wankat, K. A. Smith, Five Major Shifts in 100 Years of Engineering Education, in Proc. of the IEEE, Special Centennial Issue, (100), 2012, pp.1344-1360. https://doi.org/10.1109/JPROC.2012.2190167

[6] S. Barney, M. Khurum, K. Petersen, M. Unterkalmsteiner, and R. Jabangwe, Improving Students With Rubric-Based Self-Assessment and Oral Feedback. IEEE Trans. Education. 55(3), 2012, pp. 319-325. https://doi.org/10.1109/TE.2011.2172981

[7] C. Secolsky, and D. Denison (2011). Handbook on measurement, assessment, and evaluation in higher education, New York, NY: Routledge.

[8] S. A. Al-Yahya, and M. A. Abdel-halim. A Successful Experience of ABET Accreditation of an Electrical Engineering Program. IEEE Trans. Education., 56(2), 2013, pp.165-173. https://doi.org/10.1109/TE.2012.2206112

[9] B.M. Olds, B.M. Moskal, and R.L. Miller, Assessment in Engineering Education: Evolution, Approaches and Future Collaborations. Engineering Education, 94(1), 2015, pp. 1325. https://doi.org/10.1002/j.2168-9830.2005.tb00826.x

[10] W. Kuo, Assessment for U.S. Engineering Programs. IEEE Trans. Reliability. 55(1), 2006, pp.1-6. https://doi.org/10.1109/TR.2005.863791

[11] A. Quintana, A. Rogado, A. Gavilán, I. Martín, M. Esteban, T. Zorrilla, and J. Izard, Application of New Assessment Tools in Engineering Studies: The Rubric. IEEE Revista 
Iberoamericana de Tecnologias del Aprendizaje. 9(4), 2014, pp.139-143. https://doi.org/10.1109/RITA.2014.2363008

[12] Nilsson, James, \& Riedel, Susan, Electric Circuits. Pearson, 2015.

[13] J. Yousafzai, I. Damaj, and M. El Abd, A unified approach for assessing capstone design projects and student outcomes in computer engineering programs. IEEE Global Engineering Education Conference, 2015, pp. 333-339. https://doi.org/10.1109/EDUCON. 2015.7095993

[14] ABET accredited Program search. http://main.abet.org/aps/accreditedprogramsearch.aspx, Accessed April 2017.

[15] Electrical and Computer Engineering Department American University of Kuwait, ABET Self-Study Report for the Computer Engineering Program, ABET Symposium 2016, Florida, US, http://www.abet.org/workshops-and-events/abet-symposium/2016-self-studyreport-room/\#eac, Accessed April 2017.

[16] J. P. Somervell, Assessing Student Outcomes with Comprehensive Examinations: A Case Study. in Proc. Frontiers in Education: CS and CE Las Vegas, NV, USA, 2015, pp. 110115.

[17] W. J. Popham, Why Standardized Tests Don't Measure Educational Quality. Using Standards and Assessments, 56(6), 1999, pp. 8-15.

[18] A.L. Jones, A Metric for Assessment of ABET accreditation Student Outcome "b" - Experimental Design and Analyzing the results. in Proc., American Society for Engineering Education, Seattle, WA, USA. 2015, pp. 26.67.1-9,

[19] M. Paretti, R. Layton, S. Laguette, and Greg. Speegle, Managing and mentoring capstone design teams: Considerations and practices for faculty. Engineering Education, 27(60), 2011, pp. 1-14.

[20] South Dakota School of Mines and Technology, Rapid City, South Dakota, ABET SelfStudy Report for the Degree of Bachelor of Science in Computer Engineering, 2010. http://www.sdsmt.edu/Academics/Departments/Electrical-and-Computer-Engineering/ Docs/ABET-Self-Study-ECE-2010/ Accessed April 2017.

[21] University of Arkansas, Fayetteville, Arkansas, Fort Smith, Arkansas (Off-site), ABET Self-Study Report for the Mechanical Engineering Program, 2008. http://www.uark.edu/ua/meeg/aame/08-09/2008 ABET Self-Study.pdf, Accessed April 2017.

[22] University of Utah College of Engineering Salt Lake City, Utah, ABET Self-Study Report for the Civil Engineering Program, 2015.

http://www.civil.utah.edu/ bartlett/ABET/CVEEN\%20eac-self-study-questionnaire-20152016.pdf, Accessed April 2017.

\section{Authors}

Issam Damaj is an Associate Professor of Computer Engineering at the American University of Kuwait. Since 2011, he has been the ABET Accreditation Steering Committee Chair and the Institutional Representative of the Electrical and Computer Engineering (ECE) Department. He was the Founding Chairperson of the ECE Department and Program Lead between 2009 and 2016. His research interests include hardware/software co-design, automation, Internet-of-things applications, and engineering education. He is a Program Evaluator (PEV) with ABET Engineering Accreditation Commission, a Senior Member of the IEEE, and a Member of the ASEE.

Ashraf Zaher is an Associate Professor of Computer Engineering at the American University of Kuwait. Since 2016, he has been the Chair of the Electrical and Com- 
puter Engineering. He is a member of the ECE ABET Accreditation Steering Committee and the Chair of the ECE Academic and Curriculum Committee. His research interests include virtual engineering, nonlinear dynamics, hybrid signal processing, engineering physics, and chaos. He is a member of IEEE, AACC and AIP.

Jibran Yousafzai is an Assistant Professor of Electrical and Computer Engineering. He is the Chair of the ECE Project Evaluation Committee and a member of the ECE Industrial Advisory Board. His research interests are in the broad area of signal processing, ranging from theoretical aspects of signal analysis to applications in automatic speech recognition and resolution of robustness issues, machine learning and digital audio processing. He is a member of IEEE.

Article submitted 08 June 2017. Published as resubmitted by the authors 25 July 2017. 